\title{
Revisiting economic burdens of malaria in the face of climate change: a conceptual analysis for Ethiopia
}

Economic burdens of malaria

\author{
Amsalu Woldie Yalew \\ Potsdam Institute for Climate Impact Research (PIK), \\ Member of the Leibniz Association, Potsdam, Germany
}

Received 18 May 2020

Revised 31 August 2020 9 October 2020

Accepted 9 October 2020

\begin{abstract}
Purpose - Climate change affects the geographic and seasonal range of malaria incidence, especially, in poor tropical countries. This paper aims to attempt to conceptualize the potential economic repercussions of such effects with its focus on Ethiopia.
\end{abstract}

Design/methodology/approach - The paper is conceptual and descriptive in its design. It first reviews existing literature and evidence on the economic burdens of malaria, and the impacts of climate change on malaria disease. It then draws the economic implications of the expected malaria risk under the future climate. This is accompanied by a discussion on a set of methods that can be used to quantify the economic effects of malaria with or without climate change.

Findings - A review of available evidence shows that climate change is likely to increase the geographic and seasonal range of malaria incidence in Ethiopia. The economic consequences of even a marginal increase in malaria risk will be substantial as one considers the projected impacts of climate change through other channels, the current population exposed to malaria risk and the country's health system, economic structure and level of investment. The potential effects have the potency to require more household and public spending for health, to perpetuate poverty and inequality and to strain agricultural and regional development.

Originality/value - This paper sheds light on the economic implications of climate change impacts on malaria, particularly, in Agrarian countries laying in the tropics. It illustrates how such impacts will interact with other impact channels of climate change, and thus evolve to influence the macro-economy. The paper also proposes a set of methods that can be used to quantify the potential economic effects of malaria. The paper seeks to stimulate future research on this important topic which rather has been neglected.

Keywords Climate change, Malaria, Health, Agriculture, Economy, Ethiopia, Labor

Paper type Conceptual paper

\section{Introduction}

The biophysical and socio-economic consequences of climate change are already being observed, especially, in tropical low-income countries (IPCC, 2014). In these countries, climate change is expected to impinge on crop yields (Ray et al., 2019; Rosenzweig et al., 2014),

(C) Amsalu Woldie Yalew. Published by Emerald Publishing Limited. This article is published under the Creative Commons Attribution (CC BY 4.0) licence. Anyone may reproduce, distribute, translate and create derivative works of this article (for both commercial and non-commercial purposes), subject to full attribution to the original publication and authors. The full terms of this licence may be seen at http://creativecommons.org/licences/by/4.0/legalcode

The author would like to thank the two anonymous reviewers of the journal for their valuable suggestions and comments. He acknowledge the Open Access Publication Funds at PIK.
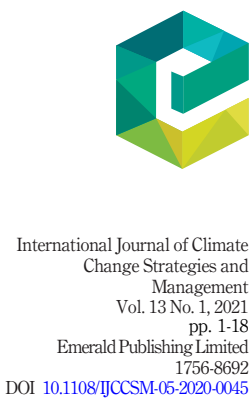
IJCCSM

13,1

livestock productivity (Escarcha et al., 2018; Rojas-Downing et al., 2017), human health (Watts et al., 2019; Niang et al., 2014) and the overall economy (Kalkuhl and Wenz, 2020; Kompas et al., 2018). The impacts on human health entail effects on health expenditures (Watts et al., 2018) and labor productivity (Flouris et al., 2018; Kjellstrom et al., 2018) which will propel through the rest of the economy (Kompas et al., 2018; Bosello et al., 2006).

The impacts of climate change on health are particularly important in Africa which currently experiences high burdens of health outcomes whose incidence and geographic range could be affected by changing temperature and precipitation patterns (Niang et al., 2014). Malaria is one of such diseases (Caminade et al., 2014; Ermert et al., 2013). Particularly in the previously cooler highlands, a warm climate may facilitate mosquito larval development, enhance vector survivorship and reproductive fitness and increase the bloodfeeding frequency and parasite sporogonic development rate (Afrane et al., 2012). The population dynamics of the mosquito vector can dramatically amplify even due to small changes in the climatic signal (Pascual et al., 2006). Changing weather and climate patterns affect the mosquito species composition differentially, and hence the transmission of malaria (Afrane et al., 2012). Then, malaria bears a large economic burden to the rural poor who have insufficient access to health services (McCarthy et al., 2000).

Due to these combined ecological and socio-economic factors, the impacts of climate change on malaria disease are particularly worrisome in the sub-Saharan Africa region. Even assuming a constant population of the year 2000, about 427 to 461 million people in Africa may be exposed to malaria by the 2040s (Ermert et al., 2013). This results in a $3 \%-4 \%$ and $6 \%$ increase in person-months exposure of malaria by $2020 \mathrm{~s}$ and $2040 \mathrm{~s}$, respectively, in tropical Africa (Ermert et al., 2013). Similarly, in the whole Africa, the person-months exposure may increase by about $16 \%-28 \%$ by 2100 (Tanser et al., 2003). These projected impacts of climate change on malaria are expected to interact with other impact channels of climate change (Niang et al., 2014) and eventually influence the macro-economy (Kompas et al., 2018; Bosello et al., 2006).

Ethiopia is a case in point. First, the seasonal and spatial transmission of malaria are projected to get worse under climate change (Ermert et al., 2012; Tanser et al., 2003). Second, even a small change in geographic range and incidence of malaria will be amplified by the growing population (FAOSTAT, 2020; WHO, 2015). Third, as the seasonal transmission of malaria (EPHI, 2016) coincides with the main agricultural season of the country (CSA, 2018), malaria often results in agricultural income loss (Deressa et al., 2007; Cropper et al., 2004). Therefore, the effects of malaria will add on other direct impacts of climate change on agriculture (Kassie et al., 2015; Evangelista et al., 2013) to eventually impinge on the overall economy as agriculture makes up 75\% of the total employment (ILO, 2019; NLFS, 2013), $37 \%$ of the gross domestic product (GDP) and $80 \%$ of the total export earnings (NBE, 2020).

As such, the potential economic consequences of climate change impacts on malaria in Ethiopia cannot be undermined. Understanding and quantifying the effects of climate variability and change on the overall disease burden in the country are therefore the critical steps for an effective public health response (Ghebreyesus et al., 2009).

The existing literature on the impacts of climate change in Ethiopia, however, barely touches the impacts on health in general and on malaria in particular (Taye et al., 2015). There are exceptions (Abrha et al., 2019; Lyon et al., 2017) which focus on the effects of climate change on the transmission and prevalence of malaria but hardly discussed the ensuing socio-economic impacts. As the subject is inherently inter-disciplinary, one of the reasons for this gap may attribute to the lack of a conceptual framework to assess the economic effects of the malaria disease burden with and without climate change. This study aims to contribute its part to fill this gap. It attempts to conceptualize and depict the chain of economic effects that may ensue 
the impacts of climate change on malaria. It, then, identifies and highlights existing methods that are useful to assess the sector-wise and economy-wide effects of malaria.

That being said, how climate variability and change will affect the spatial and temporal proliferation of mosquitos and the incidence of malaria is beyond the scope of this study. There are already a few studies addressing this issue. One can refer to research outputs from previous and ongoing projects such as the Ethiopian Malaria Prediction System by the University of Bergen and partners (Lindtjørn et al., 2014), the Epidemic Prognosis Incorporating Disease and Environmental Monitoring for Integrated Assessment by South Dakota State University and partners (Merkord et al., 2017), the Enhanced National Climate Services by the International Research Institute for Climate and Society and partners (Lyon et al., 2017), the vector-borne diseases impact modeling consortium in the Inter-Sectoral Impact Model Intercomparison Project (Caminade et al., 2014) and many other studies (Abrha et al., 2019; Ermert et al., 2013, 2012; Tanser et al., 2003).

This paper builds on the findings of the aforementioned epidemiological studies. It focuses only on the potential economic repercussions. The central objective of the paper is to raise interest, and thus stimulate future research on the socio-economic dimension of this important topic. It also seeks to inform adaptation planning, in Ethiopia and other African countries, as it discusses how the effects on malaria are going to be important and likely interact with other impacts of climate change.

\section{Climate change, malaria and potential economic effects in Ethiopia}

\subsection{Overview of malaria in Ethiopia}

About $68 \%$ of Ethiopia's landmass (where about $60 \%$ of the population lives) is prone to the risks of malaria (EPHI, 2016). Malaria transmission occurs up to 2,000 meters and occasionally in areas up to 2,300 meters elevation (PMI, 2019) putting about $47 \%$ of the population under high or moderate risks of malaria (EPHI, 2016). In terms of species, Plasmodium falciparum (P.f) and Plasmodium vivax (P.v) are the two most dominant malaria parasites with $77 \%$ of infections detected below 2,000 meters being associated with the former (PMI, 2019). The Plasmodium malariae (P.m) and Plasmodium ovale (P.o) are rare and account for hardly $1 \%$ of all confirmed malaria cases in the country (EHNRI, 2012).

The malaria risk and intensity exhibit seasonal, annual and spatial variability (PMI, 2019; EPHI, 2016). See also Figure 1 which depicts the spatial and temporal variation of malaria parasite rate based on raster data from the Malaria Atlas Project (Pfeffer et al., 2018).

Therefore, especially since 2000, Ethiopia is undertaking a wide range of measures to prevent and control malaria (Taffese et al., 2018; Deribew et al., 2017). Consequently, remarkable progress has been made in reducing the morbidity and mortality due to malaria (Girum et al., 2019; Taffese et al., 2018). Nevertheless, the prevalence rate of malaria still remains high (Taffese et al., 2018) with considerable gaps in the ownership and uses of insecticidal nets (Solomon et al., 2019; Deribew et al., 2017), and recently detected insecticide resistance (PMI, 2019). Regardless of what has been done and achieved, therefore, malaria is still one of the top ten causes of admission and morbidity (MoH, 2015a, 2014).

\subsection{Climate change and its implication for malaria}

Annual and seasonal climate variability have been common phenomena in the past five decades in Ethiopia (Gebrechorkos et al., 2018; MoEF, 2015). Since 1960, the country has observed an increase in mean annual temperatures by $1^{\circ} \mathrm{C}$, an increase in "hot nights" by $37 \%$ and an increase in "hot days" by $20 \%$ along with an overall decline but significant year-to-year volatility in precipitation (World Bank, 2020). The changes have been most 


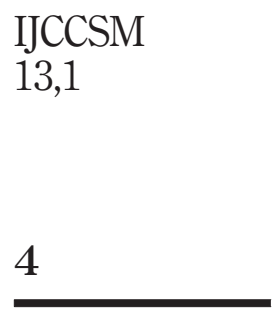

Figure 1.

Spatial distribution of P.f parasite rate (PfPR) in Ethiopia. The PfPR is scaled by logarithm 10
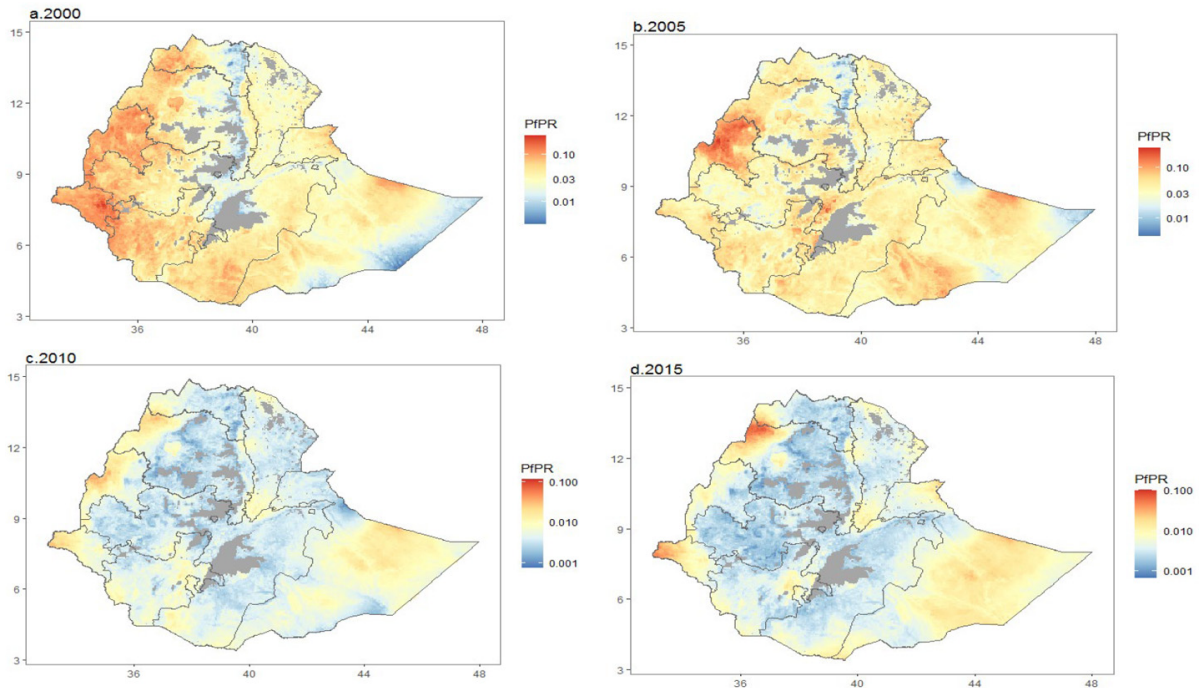

Source: Author's illustration using the malariaAtlas R package (Pfeffer et al., 2018)

noticeable from July to September, and in the central and highland regions (World Bank, 2020; Gebrechorkos et al., 2018).

Future climate projections show these past trends to continue. Temperature is expected to increase by $1.0^{\circ} \mathrm{C}(2020-2039)$, by $1.8^{\circ} \mathrm{C}(2040-2059)$, by $2.8^{\circ} \mathrm{C}(2060-2079)$ and by $3.7^{\circ} \mathrm{C}$ (2080-2099) compared to the average temperature of 1986-2005 (World Bank, 2020). According to the same report, "hot days" are expected in $19 \%-40 \%$ and $26 \%-69 \%$ of the days in a year by the 2060s and the 2090s, respectively. The most rapid increases are expected during the main rainy season (July to September). The increase in mean temperatures and frequency of weather extremes are expected as of 2020s (Gebrechorkos et al., 2019). Projections for precipitation, on the other hand, show high degrees of uncertainty and inter-annual variability (World Bank, 2020; Gebrechorkos et al., 2019).

Climatic conditions such as those projected for Ethiopia are in general suitable for mosquito reproduction (Afrane et al., 2012; Pascual et al., 2006), and thus are expected to worsen the malaria situation in the country (MoEF, 2015). The person-months of exposure in Ethiopia are projected to increase by more than $100 \%$ toward the end of the twenty-first century (Tanser et al., 2003). The prevalence of malaria will increase in all regions (Taye et al., 2015) as temperature suitability for malaria is climbing into the highlands of Ethiopia (Lyon et al., 2017). Moreover, in three selected districts in northern Ethiopia, the area suitable for malaria transmission is projected to increase by $93.8 \%$ to $113.9 \%$ and $149 \%$ to $161 \%$ by mid and end of the century, respectively (Abrha et al., 2019).

Particularly, the projection that the geographic range of malaria risks will climb to the highlands where the vast majority of the population lives is worrisome. See also Figure 2. Put differently, the climate suitability for malaria transmission will increase on par with the population (FAOSTAT, 2020). The combined trends eventually increase the number of the population exposed to the risk of malaria (MoEF, 2015). For instance, under a high emissions scenario, nearly 130 million people are projected to be at risk of malaria by 2070 (WHO, 2015) which is two-fold of the current population exposed to malaria risk (EPHI, 2016). 

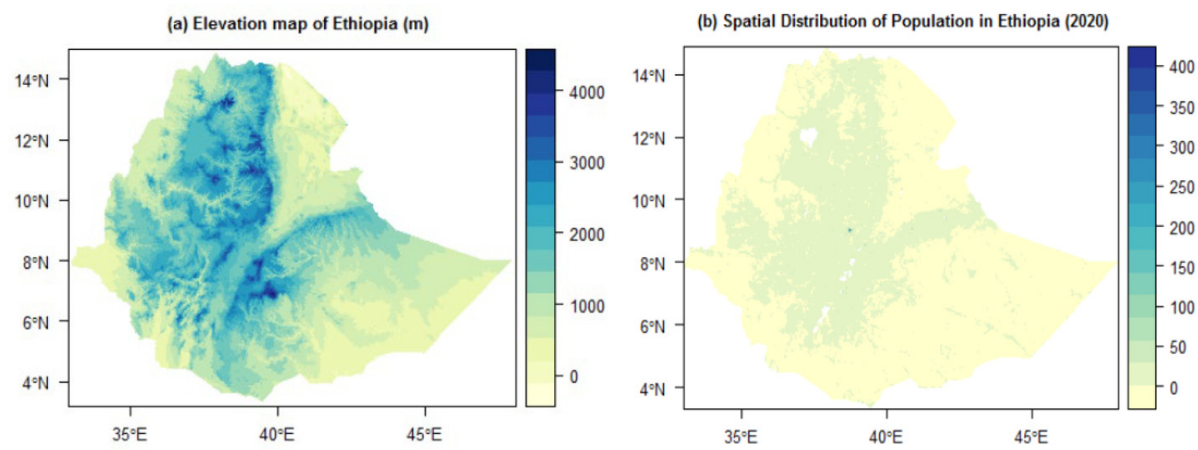

Source: Author's illustration using raster R package (Hijmans, 2020). Population data is from WorldPop(2018)

All in all, the discussion in this section indicates that the socio-economic implications of malaria under future climate are going to be substantial due to the combined effects of increasing climatic suitability for malaria transmission, size of the current population exposed to the risks of malaria and the high population growth but insufficient health facilities. The potential economic effects range from health expenditures to macroeconomic growth. The subsequent section illustrates these effects using the available evidence from past experiences in Ethiopia and other developing countries.

\subsection{Potential economic effects}

2.3.1 On health expenditures. Expenditures on malaria prevention and treatment include spending from households' out-of-pocket, government and international development assistance (Haakenstad et al., 2019). Malaria prevention involves increasing awareness of the society, strengthening the health system, procuring and distributing long-lasting insecticide-treated nets (LLINs) and conducting insecticide residual spraying (PMI, 2019), whereas malaria case management involves medical diagnosis and treatments (Berman et al., 2016). The distribution of LLINs includes provisions to new households and replacement to older ones as one LLIN is assumed to protect 1.8 persons and to last for three years (Aregawi et al., 2014). Therefore, malaria prevention and treatment expenditures are inherently recurrent.

Currently, on average, Ethiopia commits $2.5 \%$ to $5.8 \%$ of its annual government budget for the health sector to malaria (Haakenstad et al., 2019; MoH, 2015b). Spending on malaria makes up $6.4 \%$ of the total households' out-of-pocket spending for health ( $\mathrm{MoH}, 2014)$. The average unit cost of malaria treatment per case per year was between 233 ETB (12.2 US\$) and 1,575 ETB (82.5 US\$) in 2013/2014 (Berman et al., 2016). The spending on malaria per incident case in Ethiopia is already one of the highest compared to other countries trying to control malaria in Africa (Haakenstad et al., 2019).

Additional climate change-induced risks of malaria in the country (Taye et al., 2015; Tanser et al., 2003) will therefore require an extra budget for malaria from the government, households and international donors. It may further require fiscal decisions either to raise tax rates or reallocate budget from other public services, reduce households' savings and reallocate development assistance.

\section{Economic burdens of malaria}

Figure 2.

Elevation map (a) and spatial distribution of population (b) in Ethiopia 
IJCCSM

13,1

6
2.3.2 On agricultural development. The impacts of malaria on agricultural development deserve special attention due to the malaria transmission period, the economic importance of agriculture and the sensitivity of agriculture to other impact channels of climate change.

In general, the periods from September to December and from April to June are the two main malaria transmission periods in Ethiopia (EPHI, 2016). There exists regional variation as depicted in Figure 3. These malaria transmission periods in different parts of the country unfortunately coincide with the two main agricultural seasons (locally known as Meher and Belg) (CSA, 2018; Deressa et al., 2007). Besides, malaria in Ethiopia is mostly seasonal and unstable, and thus epidemic by its nature (EPHI, 2016). This implies people have little acquired immunity (Ghebreyesus et al., 2009) which contributes to a higher number of person-days lost to malaria disease. For example, previously reported productive time loss of 18 days in northern Ethiopia (Cropper et al., 2004) and 6.8 to 14.5 days in south-central Ethiopia (Deressa et al., 2007) are higher than the person-days lost (1 to 6) per malaria episode in malaria-endemic areas of Africa (Deressa et al., 2007). Of course, relatively a recent review study (Asenso-Okyere et al., 2011) reported more days of absence from work adding that this may accrue to increasing resistance to drugs.

Second, agriculture in Ethiopia is virtually rain-fed and subsistence (CSA, 2018). Labor makes up, at least, a quarter of factor inputs in the country's agriculture (Fuglie, 2015). As such, the economic consequences of morbidity attributed to malaria (MAM) on agricultural labor are substantial. The productive days lost to malaria in the Adami-Tulu district are estimated to value between ETB 94.93 (\$10.97) and 280.87 (\$32.47) per patient per episode (Deressa et al., 2007) while in the Tigray region, malaria caused a loss of ca.15\% of annual household's income (Cropper et al., 2004). One can expect the effects to get even bigger if the malaria outbreak affects many of the villagers as labor sharing is common in the main agricultural season (Ayele, 2017). Such indirect costs of malaria (due to lost productive time) are in general by far bigger than the magnitude of direct (medical costs) of malaria (Alonso et al., 2019). Indirect costs make up 75\% of the total costs related to malaria in developing countries (Deressa et al., 2007).

Figure 3. Monthly MAM in Ethiopia

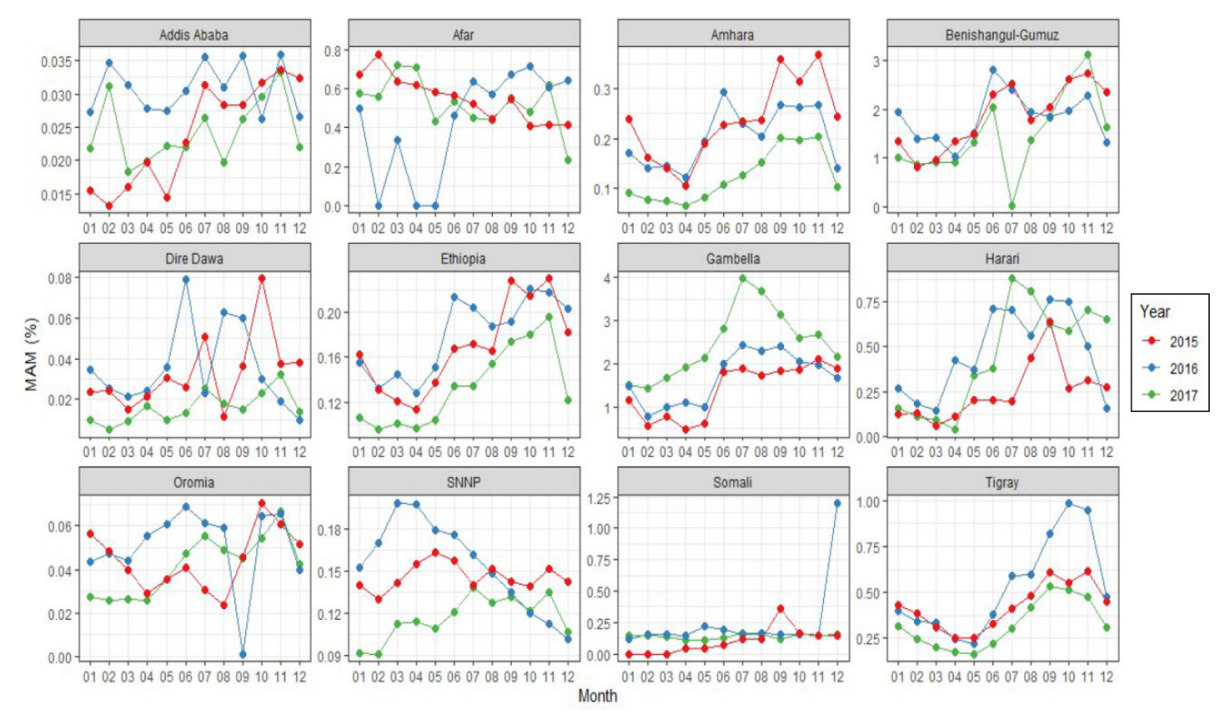

Source: Author's illustration based on data from EHDAP (2020) 
Third, climate change is expected to impinge on agricultural growth in several other ways. It is expected to reduce crop yields (Kassie et al., 2015), the area suitable to growing crops (Evangelista et al., 2013) and worsen soil erosion (Moges et al., 2020). In addition, some adaptation measures such as irrigation and micro-dams may turn to be counterproductive (Asenso-Okyere et al., 2011) as they exacerbate the risk of malaria (Kibret et al., 2019; Yewhalaw et al., 2009). As such, even a marginal increase in morbidly attributed to malaria can amplify the impacts of climate change on agriculture through other channels. The impacts of malaria on agricultural development may even be bigger than its potential impacts on the health sector expenditures. One shall also put this in the context of rising food demand (and hence prices) due to population and income growths.

2.3.3 On gender, poverty and inequality. Increasing malaria risk has also implications for gender and income inequalities. The implications for gender equity attributes to both the vulnerability of women and children to malaria (MoH, 2015a; Niang et al., 2014) and the likelihood that much of the additional productive time lost to caregiving malaria patients will be borne by women. For instance, in Ethiopia, women spend 2.5 to $3.0 \mathrm{~h}$ daily on caregiving services compared to $1.5 \mathrm{~h}$ by men (CSA, 2014). Malaria also disproportionally affects the lowest income group (Malaney, 2003) accruing to the poor housing conditions (Ayele et al., 2012) and the lack of financial means to take prevention and control measures regularly (Asenso-Okyere et al., 2011). The possession of insecticide-treated bed nets among poor households in Ethiopia is lower than the possession among non-poor households by ten percentage points (EPHI, 2016). Consequently, the average prevalence of malaria among the lowest wealth quintile is found to be $2.2 \%$ compared to $0.8 \%$ for the highest wealth quintile (EPHI, 2016). One may also consider the fact that labor is the main source of income among rural poor households where the dependency ratios are also high (NLFS, 2013). Taken together, the increasing risk of malaria will pose additional risks perpetuating the current poverty and inequality conditions in the country.

On the other hand, climate change threatens to worsen poverty in developing countries (Hertel et al., 2010) and to reverse development gains (World Bank, 2010) while previous research has documented well that national poverty (or low level of development) limits the provision of sufficient health facilities and adequate financial resources for malaria prevention and control measures (Sachs and Malaney, 2002; McCarthy et al., 2000). Ethiopia is a case in point. Today, one has to travel about $46 \mathrm{~km}$ to reach to the nearest hospital (PDC, 2018) while $57 \%$ of the total malaria spending comes from development assistance (Haakenstad et al., 2019). In other words, climate change effects on other sectors of the economy may slow down the efforts to control malaria even if new malaria risk is not assumed. Therefore, climate change will intensify the two-relationship between malaria and poverty.

2.3.4 On regional development. The incidence of malaria is uneven across the regions of Ethiopia (EPHI, 2016; MoH, 2015a) as it depends on several local environmental conditions and disease control capacities (Caminade et al., 2014; Taye et al., 2015). For instance, the monthly MAM in Benishangul-Gumuz (up to 3\%) and Gambella (up to $4 \%$ ) are by far higher than the national average (up to $0.25 \%$ ) (EHDAP, 2020). In addition, the degree to which man-made reservoirs (e.g. irrigation and dams) intensify malaria transmission is different in lowland and highland regions. For instance, mean monthly malaria incidence was found to be 2 -fold and 10 -fold higher in the lowland dam village compared to the case in midland and highland dam villages, respectively (Kibret et al., 2017).

In line with the theory of compensating wage differentials (Viscusi, 1978; Cousineau et al., 1992), one can expect such regional differences in malaria risk entail regional wage differences and hence returns to labor intensive industries such as large-scale farms. In addition, malaria affects the tourism sector (Sachs and Malaney, 2002). Thus, all in all, the

\section{Economic burdens of malaria}


IJCCSM

13,1

effects of malaria on GDP and poverty rates are non-linear across regions (Gallup and Sachs, 2001). The long-term effects may be worse if, especially, the current malarious regions (which are also economically least developed and located in the lowlands) continue to bear the largest burden of the projected risks of malaria. In such cases, malaria will not only strain regional development but also widens existing regional inequalities.

2.3.5 On the macroeconomy. The macroeconomic effects of climate change impacts on malaria can be seen from three main vantages. These are the share of public health spending, the relative importance of agriculture and the level of investment in the economy.

Government is the main health service provider in Ethiopia. Currently, public expenditure for health services accounts for about $10 \%$ of the total government budget (CSA, 2020). About $90 \%$ of the spending on malaria is covered by development assistance and government (Haakenstad et al., 2019). As such, additional budget commitment for public health (due to additional malaria cases) raises a fiscal balance issue.

Smallholder agriculture which, as discussed earlier, will likely bear the largest burden of the opportunity costs due to lost productive days is also the main economic sector in Ethiopia (NBE, 2020; NLFS, 2013). We have seen earlier that the impacts on malaria will be additional to other factors that impose risks to agricultural growth in the face of climate change. As such, even marginal agricultural labor productivity lost to malaria (or exacerbated by climate change) has repercussions for the whole economy (e.g. on food prices, GDP growth and export volumes).

Finally, the share of gross capital formation (investment) and gross domestic savings relative to GDP hovers around $35 \%$ and $20 \%$, respectively, (NBE, 2020) implying major efforts are yet required to raise domestic savings to meet investment demands. As highlighted earlier, malaria may affect gross capital formation through its effects on households' savings and government budget surplus, and on labor, investment and tourism flow to malarious areas (Sachs and Malaney, 2002; Gallup and Sachs, 2001). The current and projected risk of malaria may, for example, strain planned large-scale irrigation farms in the mid- and low-lands (MoARD, 2010) as irrigation and hydroelectric dams are found to increase the prevalence of malaria (Kibret et al., 2019, 2017; Yewhalaw et al., 2009). In that sense, climate change impacts on malaria may contribute to slowing down the pace of economic growth and structural transformation in the country (Figure 4).

To sum up, climate change impacts on malaria have the potency to strain macroeconomic growth directly and indirectly. Therefore, climate change will intensify the prevailing vicious circle between malaria and poverty and GDP growth rates (Gallup and Sachs, 2001; McCarthy et al., 2000). On the one hand, it increases the geographic range and incidence of malaria (WHO, 2015; MoEF, 2015); on the other hand, it threatens to perpetuate poverty (Hertel et al., 2010) and underdevelopment (World Bank, 2010). That is why quantifying the potential economic effects such as those discussed in this section will be important. The subsequent section is therefore devoted to discuss a set of methods drawn from both health and general economics which can be used for such exercises.

\section{Review of economic methods}

\subsection{Disability adjusted life years}

The disability-adjusted life years (DALYs) is one of widely used methods to quantify the burden of a disease. See, for example, the GBD 2017 DALYs and HALE Collaborators (2018) which applied DALYs for more 359 diseases and injuries. DALYs measure a sum of the years of life lost (YLL) due to premature mortality and the years lost due to disability (YLD) for people with a disease or its consequences (Girum et al., 2019). Alternatively, DALYs are regarded as years of healthy life lost (Deribew et al., 2017). 


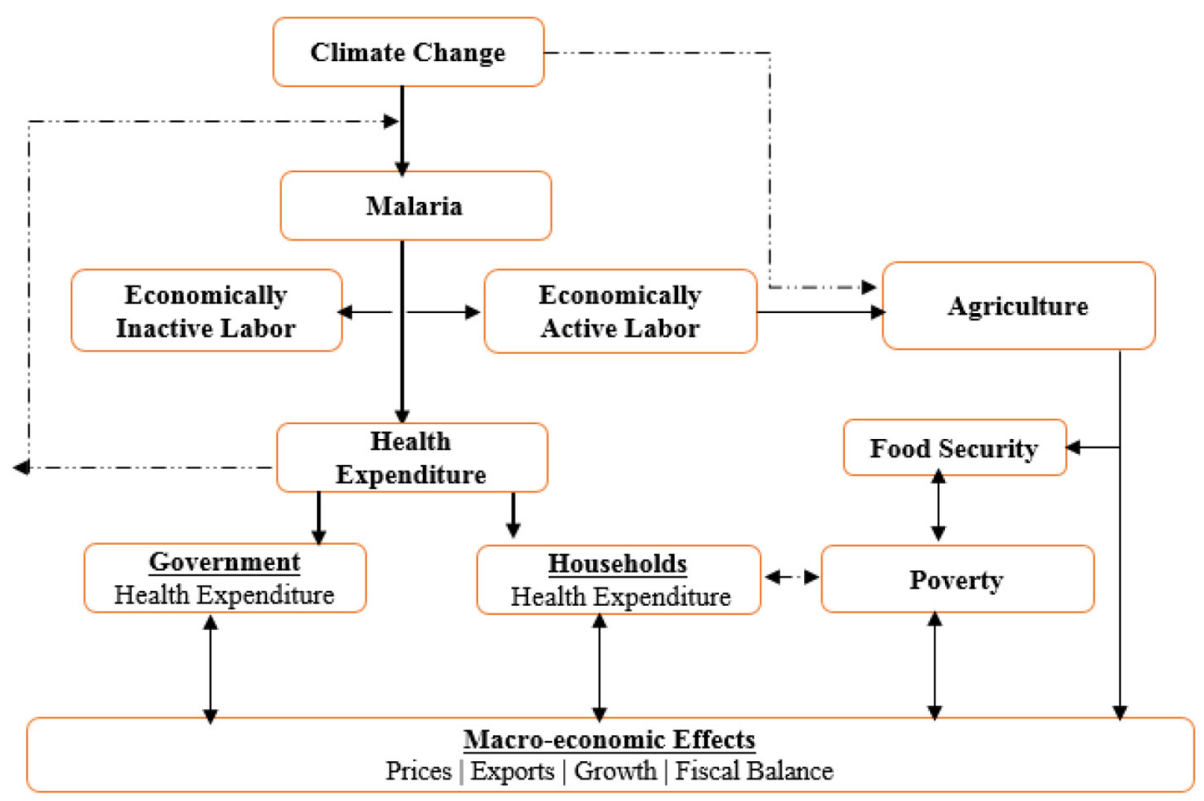

Source: Author's conceptualization and illustration
Economic burdens of malaria

Figure 4.

Schematic presentation of climate change, malaria and economic effects

Its applicability for any geographic scale and the fact that it places no monetary value for healthy life lost makes DALYs simple to use and interpret results. DALYs of a disease can be calculated as follows:

$$
D A L Y=Y L L+Y L D=(N \cdot L)+(P \cdot D W)
$$

where $N$ is the number of deaths, $L$ is the standard life expectancy at the age of death in years; and $P$ is the number of prevalent cases and $D W$ is disability (morbidity) weight.

The incremental malaria disease burden $(m)$ due to climate change can then be calculated as the difference between DALYs with future climate $(f c)$ and current climate $(c c)$ scenarios:

$$
D A L Y^{m}=D A L Y^{f c}-D A L Y^{c c}
$$

The DALYs method will particularly help to focus on the health impacts of climate changeinduced malaria.

\subsection{Cost-of-Illness}

The cost-of-illness (COI) is perhaps the most commonly applied approach to evaluate the economic burdens of malaria and other diseases (Malaney, 2003). The COI approach which has been formalized since the 1960s (Rice, 1967) is particularly applied to estimate malariainduced direct and indirect costs for households (Asante and Asenso-Okyere, 2003). The approach consists of two alternate methods. These are the human capital method that takes into account the value of lost future labor productivity to the society and the willingness-topay approach that elicits the monetary value that a given individual associates to incremental variations in his or her risk of illness or death (Malaney, 2003). 
IJCCSM 13,1

Following the standard COI formula (Malaney, 2003; Asante and Asenso-Okyere, 2003), the incremental cost of illness due to climate change $\left(\mathrm{C}^{\mathrm{m}}\right)$ can be calculated as follows:

$$
C^{m}=\sum C_{i}^{f c}-\sum C_{i}^{c c}
$$

where $\mathrm{C}^{\mathrm{fc}}$ (total COI under future climate), $\mathrm{C}^{\mathrm{cc}}$ (total COI under current climate) and $i$ are types of costs incurred due to malaria illness. The costs include private and non-private medical costs and foregone income due to reduced working capacity of labor, investment and tourism flows and decisions (e.g. regarding migration and cropping) made due to riskrelated behavior. The direct private medical costs include costs incurred by individuals for registration, consultation, drugs, hospitalization and transportation while seeking malaria treatment. Direct non-private costs include spending on malaria by governmental and nongovernmental agencies. The forgone income (indirect costs) due to morbidity and mortality of labor can be categorized as short- and long-term costs. The short-term costs are pertaining to production (and income) lost due to labor supply and productivity shocks. These costs depend on the average workdays lost per episode, the average daily wages (or earnings) per sector of employment, employment by sector and labor participation rates. The long-term costs, on the other hand, accrues to the effects on human capital formation, the value of life-time income lost due to premature death and demographic effects including fertility rates. More discussion related to this section can also be found in Malaney (2003), Asante and Asenso-Okyere (2003) and Cropper et al. (2004).

\subsection{Growth models}

Growth models are used to assess the effects of malaria on economic growth. They can include malaria (represented by proxy indices) directly as an explanatory variable (McCarthy et al., 2000; Gallup and Sachs, 2001):

$$
g=f(m, x)
$$

where $g$ is the growth rate of real GDP, $m$ is an index for malaria (e.g. the share of the total population exposed to malaria) and $x$ is a set of other determinants of GDP growth (e.g. capital and labor stocks and the degree of trade openness).

Alternatively, growth models can incorporate the effects of malaria indirectly as changes in labor productivity and/or supply. Consider, for example, a stylized Ramsey-type growth model (Kalkuhl and Wenz, 2020):

$$
Y=A . f(K, \alpha L)
$$

where:

$Y$ is economic output (GDP), $A$ is total factor productivity (TFP), $K$ is capital stock, $\alpha$ and $L$ are labor productivity and supply, respectively.

In either of the approaches, growth models are useful tools to draw lessons from the past to glean information about the potential economic effects of malaria under future climate.

\subsection{Partial equilibrium models}

Partial equilibrium models are often used to simulate the effects of exogenous changes such policy reforms and demand and supply shocks on a given economic sector (Cardenete et al., 2012). Partial equilibrium models consider both supply and demand sides in which equilibrium prices are set to clear the market. The models can be static or recursively dynamic. 
In light of the discussion in Section 2.4, parts of the economic burdens of climate change impacts on malaria can be gleaned through dynamic partial equilibrium models of agriculture. The models can also be multi-regional to capture projected geo-specific risks and their propagation to the rest of the regions through inter-regional trade and migration, for example.

Let us assume an agricultural production represented by a constant elasticity of substitution (CES) function:

$$
Y=A \cdot\left[\sum_{i} \delta_{i} \cdot\left[\alpha_{i} \cdot X_{i}\right]^{-\rho}\right]^{\frac{1}{-\rho}}
$$

where $Y$ is agricultural output, $A$ is TFP (or scale parameter), $\delta$ and $\alpha$ are, respectively, the share and factor-specific productivity parameters of input $i$ (e.g. labor, capital, land) and $\rho$ is the elasticity of factor substitution. Malaria effects can thus be introduced as changes in labor productivity $\left(\alpha_{\text {labor }}\right)$ or TFP (A).

In the case of a multi-regional partial equilibrium model for agriculture, outputs from different regions can be aggregated using a CES function such as the one given below (Lofgren et al., 2002):

$$
Y_{A}=\gamma \cdot\left[\sum_{r}\left[\theta_{r} \cdot Y_{r}\right]^{-\rho}\right]^{\frac{1}{\rho-1}}
$$

where $Y_{A}$ is country-wide agricultural output, $\gamma$ is a shift parameter for aggregation, $\Theta_{\mathrm{r}}$ is the proportion of agricultural output from region $r, Y_{r}$ is agricultural output from region $r$ and $\rho$ an aggregation function exponent.

Depending on the structure of the partial equilibrium model at hand, among others, the effects of climate change (through the additional risk of malaria) on agricultural prices, GDP, employment and exports can be simulated directly. Such models are also suitable to assess the multiple impacts of climate change (e.g. on labor productivity due to malaria or heatstress, on crop yields, on areas suitable for crop cultivation and on livestock size and productivity) simultaneously.

The main drawback of partial equilibrium models for agriculture accrues to the fact that the models are partial, and hence do not account for all economic flows (Robinson et al., 2014). In our case, for example, they do not include the direct private and non-private health expenditures on malaria which are often recorded in health accounts.

\subsection{Computable general equilibrium models}

Computable general equilibrium (CGE) models address the inherent limitation of partial equilibrium models. The underlying premise of CGE models is that an economy is a system of interdependent components (agents, markets, regions and commodities). Accordingly, CGE models presume that an outcome of any change in the economy is determined by all direct, indirect and induced (feedback) effects (Cardenete et al., 2012), and thus a CGE model consists of a system of equations that describe an economy as a whole and the interactions among its part (Burfisher, 2011; Hosoe et al., 2010). CGE models can be single-period or dynamic; country-wide or multi-regional.

CGE models are best suited to assess the multiple impacts of climate change (e.g. on malaria, crop yields and hydropower) on multiple sectors (e.g. on health, agriculture and energy) simultaneously and on different components of the economy (e.g. on households, industries and the macro-economy). For example, CGE models can include malaria-induced effects as changes in one or a combination of:

\section{Economic burdens of malaria}


IJCCSM

13,1

- Labor productivity in agriculture;

- Public expenditure on health services;

- Health demand (spending) by households;

- Inter-regional labor mobility;

- Investment and tourism demands in some regions; and

- Transfers (development assistance) from the rest of the world to the Ethiopian economy.

Let us zoom into three of these possibilities for illustration.

First, we can include as changes in labor-specific or TFP in agricultural activities as in equations (4a) and (4b). The difference here is that the CGE model results can show the outcomes on households' welfare and on the performance of the overall economy as they include indirect and induced effects from other sectors.

Second, we can incorporate as changes in commodity-specific shares in households' consumption basket. In CGE models, different household groups (usually classified on the basis of income - poor and non-poor, residence - rural and urban or geographic locations highlands and lowlands, etc.) are assumed to maximize their utility derived from the consumption of goods and services subject to their total budget (income) constraint (Lofgren et al., 2002). For example:

$$
U\left(x_{1}, \ldots, x_{n}\right)=\prod_{i=1}^{n} x_{i}^{\theta_{i}}
$$

where $x_{i}$ is the consumption of commodity $i$ and $\Theta_{\mathrm{i}}$ is the proportion of commodity $i$ in the consumption budget of households. The sum of $\Theta_{\mathrm{i}}$ equals to one. In CGE modeling tradition, the $\Theta_{i}$ is known as a share parameter and is usually modeled as an exogenous parameter during the model calibration (Lofgren et al., 2002; Hosoe et al., 2010). For example, increasing households' expenditure to prevent and/or treat the malaria disease burden will raise households' consumption of "malaria-related health services," thus, affecting the demand for other commodities as the total consumption budget is usually held constant. The ultimate effect on the rest of the economy depends, of course, on the initial value and the marginal increase in the aforementioned share parameter.

Third, we can include as changes in the government (also called public sector) spending. Government budget balance represents the difference between government revenue and government expenditure or "consumption":

$$
G S=\sum_{r=1}^{R} t_{r} \cdot Q_{r}-\sum_{e=1}^{E} p_{e} \cdot Q_{e}
$$

Oftentimes, CGE models are calibrated holding government "consumption" of goods and services $\left(\mathrm{Q}_{\mathrm{e}}\right)$ and tax rates $\left(\mathrm{t}_{\mathrm{r}}\right)$ fixed (Lofgren et al., 2002; Hosoe et al., 2010). As such, for a given set of tax rates, an increase in the government consumption (i.e. providing services) of malaria-related measures will directly influence the government budget surplus (savings), and hence the total investment.

CGE models are often calibrated to a social accounting matrix (SAM) of a given economy. A standard SAM usually contains aggregated sectors. For example, it may not have malaria-specific transactions in the public budget (services) and households' consumption accounts. In that case, one shall first split malaria-related transactions and inputs from the transactions and inputs associated with the aggregate health service accounts. 


\section{Conclusions}

This paper attempted to conceptualize and discuss the potential economic effects that may ensue the impacts of climate change on malaria in Ethiopia. It particularly discusses how the sector-wise and economy-wide impacts of the projected prevalence of malaria reported elsewhere (WHO, 2015; MoEF, 2015; Caminade et al., 2014; Ermert et al., 2013) may matter particularly in light of the spatial distribution of the current and projected population and the health expenditure and macroeconomic structures of the country. It is important to note here that these potential impacts of climate change on malaria will be in addition to already projected impacts on agriculture (Kassie et al., 2015), water and energy resources (MoWIE, 2016) and heat-stress effects on labor working capacity (ILO, 2019).

Overall, the paper tried to argue why the economic implications of climate change impacts on malaria should not be underestimated. Therefore, more quantitative studies from health economics (e.g. on additional malaria DALYs, direct and indirect costs-of-illness), agricultural economics (e.g. on partial equilibrium effects) and macroeconomics (e.g. on general equilibrium and growth effects) are highly needed. Studies applying partial or general equilibrium models will particularly be important to assess both the direct and indirect effects of malaria and their possible interaction with other impact channels. In parallel, adaptation policy planners should start explicitly accounting the sector-wise (or health) effects of malaria along with their possible interactions with other impact channels of climate change in different sectors and regions.

\section{References}

Abrha, H., Hagos, H., Brhane, E., Hadgu, M. and Mamo, G. (2019), "Spatio-temporal dynamics of malaria expansion under climate change in semi-arid areas of Ethiopia", Environmental Hazards, Vol. 18 No. 5, pp. 400-413.

Afrane, Y.A., Githeko, A.K. and Yan, G. (2012), "The ecology of anopheles mosquitoes under climate change: case studies from the effects of deforestation in east African highlands", Annals of the New York Academy of Sciences, Vol. 1249 No. 1, pp. 204-210.

Alonso, S., Chaccour, C.J., Elobolobo, E., Nacima, A., Candrinho, B., Saifodine, A., Saute, F., Robertson, M. and Zulliger, R. (2019), "The economic burden of malaria on households and the health system in a high transmission district of Mozambique", Malaria Journal, Vol. 18 No. 1.

Aregawi, M., Lynch, M., Bekele, W., Kebede, H., Jima, D., Taffese, H.S., Yenehun, M.A., Lilay, A., Williams, R., Thomson, M., Nafo-Traore, F., Admasu, K., Gebreyesus, T.A. and Coosemans, M. (2014), "Time series analysis of trends in malaria cases and deaths at hospitals and the effect of antimalarial interventions, 2001-2011, Ethiopia", PLoS One, Vol. 9 No. 11.

Asante, F.A. and Asenso-Okyere, K. (2003), "Economic burden of Malaria in Ghana”, Technical Report, Regional Office for Africa, World Health Organization, Brazzaville.

Asenso-Okyere, K., Asante, F.A., Tarekegna, J. and Andam, K.S. (2011), "A review of the economic impact of malaria in agricultural development", Agricultural Economics, Vol. 42 No. 3, pp. 293-304.

Ayele, F. (2017), "Malaria epidemics in Dembia, Northwest Ethiopia 1952-1953”, Ethiopian Journal of Health and Development, Vol. 31 No. 1, pp. 57-63.

Ayele, D.G., Zewotir, T.Z. and Mwambi, H.G. (2012), "Prevalence and risk factors of malaria in Ethiopia", Malaria Journal, Vol. 11 No. 1.

Berman, P., Alebachew, A., Mann, C., Agarwal, A. and Abdella, E. (2016), "Costs of publicly funded primary care facilities, departments, and exempted services in Ethiopia", Paper 1, Primary Health Care Cost Study Series, Harvard T.H. Chan School of Public Health, MA.

Bosello, F., Roson, R. and Tol, R. (2006), "Economy-wide estimates of the implication of climate change: human health", Ecological Economics, Vol. 58 No. 3, pp. 579-591. 
IJCCSM

13,1

Burfisher, M.F. (2011), Introduction to Computable General Equilibrium Models, Cambridge University Press, New York, NY.

Caminade, C., Kovats, S., Rocklov, J., Tompkins, A.M., Morse, A.P., Colón-González, F.J., Stenlund, H., Martens, P. and Lloyd, S.J. (2014), "Impact of climate change on global malaria distribution", Proceedings of the National Academy of Sciences, Vol. 111 No. 9, pp. 3286-3291.

Cardenete, M.A., Guerra, A.I. and Sancho, F. (2012), Applied General Equilibrium: An Introduction, Springer-Verlag, Berlin.

Cousineau, J., Lacroix, R. and Girard, A. (1992), "Occupational hazard and wage compensating differentials", The Review of Economics and Statistics, Vol. 74 No. 1, pp. 166-169.

Cropper, M.L., Haile, M., Lampietti, J., Poulos, C. and Whittington, D. (2004), "The demand for a malaria vaccine: evidence from Ethiopia”, Journal of Development Economics, Vol. 75 No. 1, pp. 303-318.

CSA (2014), Ethiopia Time Use Survey 2013: How Women and Men Spend Their Time, Central Statistical Agency (CSA), Federal Democratic Republic of Ethiopia, Addis Ababa.

CSA (2018), Agricultural Sample Survey: 2017/18, Central Statistical Agency (CSA), Federal Democratic Republic of Ethiopia, Addis Ababa.

CSA (2020), Annual Statistical Abstract Indicators: Public Finance, Central Statistical Agency (CSA), Federal Democratic Republic of Ethiopia, Addis Ababa.

Deressa, W., Hailemariam, D. and Ali, A. (2007), "Economic costs of epidemic malaria to households in rural Ethiopia”, Tropical Medicine and International Health, Vol. 12 No. 10, pp. 1148-1156.

Deribew, A., Dejene, T., Kebede, B., Tessema, G.A., Melaku, Y.A., Misganaw, A., Gebre, T., Hailu, A., Biadgilign, S., Amberbir, A., Yirsaw, B.D., Abajobir, A.A., Shafi, O., Abera, S.F., Negussu, N., Mengistu, B., Amare, A.T., Mulugeta, A., Mengistu, B., Tadesse, Z., Sileshi, M., Cromwell, E., Glenn, S.D., Deribe, K. and Stanaway, J.D. (2017), "Incidence, prevalence and mortality rates of malaria in Ethiopia from 1990 to 2015: analysis of the global burden of diseases 2015”, Malaria Journal, Vol. 16 No. 1.

EHNRI (2012), Ethiopia National Malaria Indicator Survey 2011, Ethiopian Health and Nutrition Research Institute (EHNRI), Federal Democratic Republic of Ethiopia, Addis Ababa.

EPHI (2016), Ethiopia National Malaria Indicator Survey 2015, Ethiopian Public Health Institute (EPHI), Federal Democratic Republic of Ethiopia, Addis Ababa.

Ermert, V., Fink, A.H. and Paeth, H. (2013), "The potential effects of climate change on malaria transmission in Africa using bias-corrected regionalized climate projections and a simple malaria seasonality model", Climatic Change, Vol. 120 No. 4, pp. 741-754.

Ermert, V., Fink, A.H., Morse, A.P. and Paeth, H. (2012), "The impact of regional climate change on malaria risk due to greenhouse forcing and land-use changes in tropical Africa", Environmental Health Perspectives, Vol. 120 No. 1, pp. 77-84.

Escarcha, J.F., Lassa, J.A. and Zander, K.K. (2018), "Livestock under climate change: a systematic review of impacts and adaptation”, Climate, Vol. 6 No. 3.

Ethiopian Health Data Analytics Platform (EHDAP) (2020), "Malaria”, available at: https://moh-public. ehdap.com (accessed 20 March 2020).

Evangelista, P., Young, N. and Burnett, J. (2013), "How will climate change spatially affect agriculture production in Ethiopia? Case studies of important cereal crops", Climatic Change, Vol. 119 Nos 3/4, pp. 855-873.

FAOSTAT (2020), "Food and agriculture data", available at: www.fao.org/faostat/en/\#data (accessed 19 March 2020).

Flouris, A.D., Dinas, P.C., Ioannou, L.G., Nybo, L., Havenith, G., Kenny, G.P. and Kjellstrom, T. (2018), "Workers' health and productivity under occupational heat strain: a systematic review and Meta-analysis", Lancet Planet Health, Vol. 2, pp. 521-531. 
Fuglie, K.O. (2015), “Accounting for growth in global agriculture”, Bio-Based and Applied Economics, Vol. 4 No. 3, pp. 201-234.

Gallup, J.L. and Sachs, J.D. (2001), "The economic burden of malaria”, The American Journal of Tropical Medicine and Hygiene, Vol. 64 No. 1, pp. 85-96.

GBD 2017 DALYs and HALE Collaborators (2018), "Global, regional, and national disability-adjusted life-years (DALYs) for 359 diseases and injuries and healthy life expectancy (HALE) for 195 countries and territories, 1990-2017: a systematic analysis for the global burden of disease study 2017", Lancet, Vol. 392, pp. 1859-1922.

Gebrechorkos, S.H., Hülsmann, S. and Bernhofer, C. (2018), "Changes in temperature and precipitation extremes in Ethiopia, Kenya, and Tanzania”, International Journal of Climatology, Vol. 39 No. 1, pp. 18-30.

Gebrechorkos, S.H., Hülsmann, S. and Bernhofer, C. (2019), "Regional climate projections for impact assessment studies in east Africa", Environmental Research Letter, Vol. 14.

Ghebreyesus, T.A., Tadesse, Z., Jima, D., Bekele, E., Mihretie, A., Yihdego, Y.Y., Dinku, T., Connor, S.J. and Rogers, D.P. (2009), "Using climate information in the health sector", Field Actions Science Reports, Vol. 2 No. 1, pp. 63-67.

Girum, T., Shumbej, T. and Shewangizaw, M. (2019), "Burden of malaria in Ethiopia, 2000-2016: findings from the global health estimates 2016", Tropical Disease, Travel Medicine and Vaccines, Vol. 5 No. 1.

Haakenstad, A., Harle, A.C., Tsakalos, G., Micah, A.E. and Joseph L Dieleman, J.L. (2019), "Tracking spending on malaria by source in 106 countries, 2000-16: an economic modelling study", The Lancet Infectious Diseases, Vol. 19 No. 7, pp. 703-716.

Hertel, T.W., Burke, M.B. and Lobell, D.B. (2010), "The poverty implications of climate-induced crop yield changes by 2030", Global Environmental Change, Vol. 20 No. 4, pp. 577-585.

Hijmans, R.J. (2020), "Raster: geographic data analysis and modeling", R package version 3.3-13, available at: https://CRAN.R-project.org/package=raster (accessed 20 August 2020).

Hosoe, N., Gasawa, K. and Hashimoto, H. (2010), Textbook of Computable General Equilibrium Modelling, Palgrave Macmillan, London.

ILO (2019), Working on a Warmer Planet: The Impact of Heat Stress on Labour Productivity and Decent Work, The International Labour Office (ILO), Geneva.

IPCC (2014), "Climate change 2014: synthesis report”, Contribution of Working Groups I, II and III to the Fifth Assessment Report of the Intergovernmental Panel on Climate Change (IPCC), Geneva.

Kalkuhl, M. and Wenz, L. (2020), "The impact of climate conditions on economic production: evidence from a global panel of regions", Journal of Environmental Economics and Management, Vol. 103.

Kassie, B.T., Asseng, S., Rotter, R.P., Hengsdijk, H., Ruane, A.C. and Van Ittersum, M.K. (2015), "Exploring climate change impacts and adaptation options for maize production in the Central Rift Valley of Ethiopia using different climate change scenarios and crop models", Climatic Change, Vol. 129 Nos 1/2, pp. 145-158.

Kibret, S., Wilson, G.G., Ryder, D., Tekie, H. and Beyene Petros, B. (2017), "Malaria impact of large dams at different eco-epidemiological settings in Ethiopia", Tropical Medicine and Health, Vol. 45 No. 1.

Kibret, S., Wilson, G.G., Ryder, D., Tekie, H. and Petros, B. (2019), "Environmental and meteorological factors linked to malaria transmission around large dams at three ecological settings in Ethiopia”, Malaria Journal, Vol. 18 No. 1.

Kjellstrom, T., Freyberg, C., Lemke, B., Otto, M. and Briggs, D. (2018), "Estimating population heat exposure and impacts on working people in conjunction with climate change", International Journal of Biometeorology, Vol. 62 No. 3, pp. 291-306.

Kompas, T., Ha, P.V. and Che, T.N. (2018), "The effects of climate change on GDP by country and the global economic gains from complying with the Paris climate accord", Earth's Future, Vol. 6 No. 8, pp. 1153-1173. 
IJCCSM

13,1

Lindtjørn, B., Loha, E., Deressa, W., Balkew, M., Gebremichael, T., Sorteberg, A., Woyessa, A., Animut, A., Diriba, K., Massebo, F., Viste, E., Lunde, T.M. and Tesfahun, D. (2014), "Strengthening malaria and climate research in Ethiopia", Malaria Journal, Vol. 13, p. 56.

Lofgren, H., Harris, L.R. and Robinson, S. (2002), "A standard computable general equilibrium (CGE) model in GAMS", Microcomputers in Policy Research, No. 5, International Food Policy Research Institute (IFPRI), Washington, DC.

Lyon, B., Dinku, T., Raman, A. and Thomson, M.C. (2017), "Temperature suitability for malaria climbing the Ethiopian highlands", Environmental Research Letters, Vol. 12 No. 6.

McCarthy, F.D., Wolf, H. and Wu, Y. (2000), “The Growth Costs of Malaria”, Working Paper No.7541, National Bureau of Economic Research (NBER), Cambridge.

Malaney, P. (2003), "Micro-Economic approaches to evaluating the burden of malaria", CID Faculty Working Paper No. 99, Harvard University, Cambridge.

Merkord, C.L., Liu, Y., Mihretie, A., Gebrehiwot, T., Awoke, W., Bayabil, E., Henebry, G.M., Kassa, G.T., Lake, M. and Wimberly, M.C. (2017), "Integrating malaria surveillance with climate data for outbreak detection and forecasting: the EPIDEMIA system", Malaria Journal, Vol. 16 No. 1.

MoARD (2010), Ethiopia's Agricultural Sector Policy and Investment Framework: 2010-2020, Ministry of Agriculture and Rural Development (MoARD), Federal Democratic Republic of Ethiopia, Addis Ababa.

MoEF (2015), Ethiopia's Second National Communication to the United Nations Framework Convention on Climate Change (UNFCCC), Ministry of Environment and Forest (MoEF) Federal Democratic Republic of Ethiopia, Addis Ababa.

Moges, D.M., Kmoch, A., Bhat, H.G. and Uuemaa, E. (2020), "Future soil loss in highland Ethiopia under changing climate and land use", Regional Environmental Change, Vol. 20 No. 1.

MoH (2014), Ethiopia's Fifth National Health Accounts 2010/11, Ministry of Health (MoH), Federal Democratic Republic of Ethiopia, Addis Ababa, Ethiopia.

MoH (2015a), Health and Health Related Indicator: 2014/15, Ministry of Health (MoH), Federal Democratic Republic of Ethiopia, Addis Ababa, Ethiopia.

MoH (2015b), Health Sector Transformation Plan: 2015/16-2019/20, Ministry of Health (MoH), Federal Democratic Republic of Ethiopia, Addis Ababa.

MoWIE (2016), Ethiopia's Climate-Resilient Green Economy: Climate Resilience Strategy - Water and Energy, Ministry of Water, Irrigation and Energy (MoWIE), Federal Democratic Republic of Ethiopia, Addis Ababa.

NBE (2020), Annual Economic Report 2018/2019, National Bank of Ethiopia (NBE), Federal Democratic Republic of Ethiopia, Addis Ababa.

Niang, I., Ruppel, O.C., Abdrabo, M.A., Essel, A., Lennard, C., Padgham, J. and Urquhart, P. (2014), "Africa", in Barros, V.R., Field, C.B., Dokken, D.J., Mastrandrea, M.D., Mach, K.J., Bilir, T.E., Chatterjee, M., Ebi, K.L., Estrada, Y.O., Genova, R.C., Girma, B., Kissel, E.S., Levy, A.N., MacCracken, S., Mastrandrea, P.R. and White L.L. (Eds), Climate Change 2014: Impacts, Adaptation, and Vulnerability. Part B: Regional Aspects, Cambridge University Press, Cambridge, pp. 1199-1265.

NLFS (2013), Statistical Report on the 2013 National Labor Force Survey, Central Statistical Agency (CSA), Federal Democratic Republic of Ethiopia, Addis Ababa.

Pascual, M., Ahumada, J.A., Chaves, L.F., Rodo, X. and Bouma, M. (2006), "Malaria resurgence in the East African highlands: temperature trends revisited", Proceedings of the National Academy of Sciences, Vol. 103 No. 15, pp. 5829-5834.

PDC (2018), Poverty and Economic Growth in Ethiopia: 1995/96-2015/16, Planning and Development Commission (PDC), Federal Democratic Republic of Ethiopia, Addis Ababa.

Pfeffer, D.A., Lucas, T.C., May, D., Harris, J., Rozier, J., Twohig, K.A., Dalrymple, U., Guerra, C.A., Moyes, C.L., Thorn, M., Nguyen, M., Bhatt, S., Cameron, E., Weiss, D.J., Howes, R.E., Battle, K.E., 
Gibson, H.S. and Gething, P.W. (2018), "malariaAtlas: an R interface to global malariometric data hosted by the malaria atlas project", Malaria Journal, Vol. 17 No. 1.

Ray, D.K., West, P.C., Clark, M., Gerber, J.S. and Prishchepov, A.V., C., S. (2019), “Climate change has likely already affected global food production", PLoS One, Vol. 14 No. 5.

Rice, D.P. (1967), "Estimating the cost of illness", American Journal of Public Health and the Nations Health, Vol. 57 No. 3, pp. 424-440.

Robinson, S., van Meijl, H., Willenbockel, D., Valin, H., Fujimori, S., Masui, T., Sands, R., Wise, M., Calvin, K., Havlik, P., Mason d'Croz, D., Tabeau, A., Kavallari, A., Schmitz, C., Dietrich, J.P. and von Lampe, M. (2014), "Comparing supply-side specifications in models of global agriculture and the food system", Agricultural Economics, Vol. 45 No. 1, pp. 21-35.

Rojas-Downing, M.A., Nejadhashemi, A.P., Harrigan, T. and Woznicki, S.A. (2017), "Climate change and livestock: impacts, adaptation, and mitigation", Climate Risk Management, Vol. 16, pp. 145-163.

Rosenzweig, C., Elliott, J., Deryng, D., Ruane, A.C., Müller, C., Arneth, A., Boote, K.J., Folberth, C., Glotter, M., Khabarov, N., Neumann, K., Piontek, F., Pugh, T.A.M., Schmid, E., Stehfest, E., Yang, H. and Jones, J.W. (2014), "Assessing agricultural risks of climate change in the 21st century in a global gridded crop model intercomparison", Proceedings of the National Academy of Sciences, Vol. 111 No. 9, pp. 3268-3273.

Sachs, J. and Malaney, P. (2002), "The economic and social burden of malaria", Nature, Vol. 415 No. 6872, pp. 680-685.

Solomon, T., Loha, E., Deressa, W., Gari, T., Overgaard, H.J. and Lindtjørn, B. (2019), "Low use of longlasting insecticidal nets for malaria prevention in South-Central Ethiopia: a community-based cohort study", PLoS One, Vol. 14 No. 1.

Taffese, H.S., Hemming-Schroeder, E., Koepfli, C., Tesfaye, G., Lee, M., Kazura, J., Yan, G. and Zhou, G. (2018), "Malaria epidemiology and interventions in Ethiopia from 2001 to 2016", Infectious Diseases of Poverty, Vol. 7 No. 1.

Tanser, F.C., Sharp, B. and Le Suer, D. (2003), "Potential effect of climate change on malaria transmission in Africa", The Lancet, Vol. 362 No. 9398, pp. 1792-1798.

Taye, G., Kaba, M., Woyessa, A., Deressa, W., Simane, B., Kumie, A. and Berhane, G. (2015), "Modeling effect of climate variability on malaria in Ethiopia", Ethiopian Journal of Health Development, Vol. 29 No. 3, pp. 183-196.

The President's Malaria Initiative (PMI) (2019), “Ethiopia: Malaria operational plan FY 2019”, available at: www.pmi.gov (accessed 28 April 2020).

Viscusi, W.K. (1978), "Wealth effects and earnings premiums for job hazards", The Review of Economics and Statistics, Vol. 60 No. 3, pp. 408-416.

Watts, N., Amann, M., Arnell, N., Ayeb-Karlsson, S., Belesova, K., Berry, H., Bouley, T., Boykoff, M., Byass, P., Cai, W., Campbell-Lendrum, D., Chambers, J., Daly, M., Dasandi, N., Davies, M., Depoux, A., Dominguez-Salas, P., Drummond, P., Ebi, K.L., Ekins, P., Montoya, L.F., Fischer, H., Georgeson, L., Grace, D., Graham, H., Hamilton, I., Hartinger, S., Hess, J., Kelman, I., Kiesewetter, G., Kjellstrom, T., Kniveton, D., Lemke, D., Liang, L., Lott, M., Lowe, R., Sewe, M.O., Martinez-Urtaza, J., Maslin, M., McAllister, L., Mikhaylov, S.J., Milner, J., Moradi-Lakeh, M., Morrissey, K., Murray, K., Nilsson, M., Neville, T., Oreszczyn, T., Owfi, F., Pearman, O., Pencheon, D., Pye, S., Rabbaniha, M., Robinson, E., Rocklöv, J., Saxer, O., Schütte, S., Semenza, J.C., Shumake-Guillemot, J., Steinbach, R., Tabatabaei, M., Tomei, J., Trinanes, J., Wheeler, N., Wilkinson, P., Gong, P., Montgomery, H. and Costello, A. (2018), "The 2018 report of the lancet countdown on health and climate change: shaping the health of nations for centuries to come", The Lancet, Vol. 392 No. 10163, pp. 2479-2514.

Watts, N., Amann, M., Arnell, N., Ayeb-Karlsson, S., Belesova, K., Boykoff, M., Byass, P., Cai, W., Campbell-Lendrum, D., Capstick, S., Chambers, J., Dalin, C., Daly, M., Dasandi, N., Davies, M., Drummond, P., Dubrow, R., Ebi, K.L., Eckelman, E., Ekins, P., Escobar, L.E., Montoya, L.F., Georgeson, L., Graham, H., Haggar, P., Hamilton, I., Hartinger, S., Hess, J., Kelman, I., 
IJCCSM

13,1

18
Kiesewetter, G., Kjellstrom, T., Kniveton, D., Lemke, B., Liu, Y., Lott, M., Lowe, R., Sewe, M.O., Martinez-Urtaza, J., Maslin, M., McAllister, L., McGushin, A., Mikhaylov, S.J., Milner, J., MoradiLakeh, M., Morrissey, K., Murray, K., Munzert, S., Nilsson, M., Neville, T., Oreszczyn, T., Owfi, F., Pearman, O., Pencheon, D., Phung, D., Pye, S., Quinn, R., Rabbaniha, M., Robinson, E., Rocklöv, J., Semenza, J.C., Sherman, J., Shumake-Guillemot, J., Tabatabaei, M., Taylor, J., Trinanes, J., Wilkinson, P., Costello, A., Gong, P. and Montgomery, H. (2019), "The 2019 report of the lancet countdown on health and climate change: ensuring that the health of a child born today is not defined by a changing climate", The Lancet, Vol. 394 No. 10211, pp. 1836-1878.

WHO (2015), "Climate and health country profile-2015: Ethiopia”, The World Health Organization (WHO), available at: https://apps.who.int/iris/handle/10665/208861 (accessed 20 August 2020).

World Bank (2010), "World development report 2010", available at: http://hdl.handle.net/10986/4387 (accessed 26 August 2020).

World Bank (2020), "Climate risk country profile: Ethiopia”, available at: https://climateknowledgeportal. worldbank.org/country/ethiopia (accessed 15 August 2020).

WorldPop (2018), "Global high resolution population denominators project”, available at: www.worldpop. org/doi/10.5258/SOTON/WP00645 (accessed 15 August 2020).

Yewhalaw, D., Legesse, W., Van Bortel, W., Gebre-Selassie, S., Kloos, H., Duchateau, L. and Speybroeck, N. (2009), "Malaria and water resource development: the case of Gilgel-Gibe hydroelectric dam in Ethiopia”, Malaria Journal, Vol. 8 No. 1.

\section{Further reading}

R Core Team (2020), "R: a language and environment for statistical computing", available at: www.Rproject.org/ (accessed 10 August 2020).

\section{Corresponding author}

Amsalu Woldie Yalew can be contacted at: yalew@pik-potsdam.de

For instructions on how to order reprints of this article, please visit our website: 